\title{
Correction to: Does organizational formalization facilitate voice and helping organizational citizenship behaviors? It depends on (national) uncertainty norms
}

\author{
Ronald Fischer ${ }^{1}$, \\ Maria Cristina Ferreira ${ }^{2}$, \\ Nathalie Van Meurs ${ }^{3}$, \\ Kubilay Gok ${ }^{4}$, Ding-Yu Jiang ${ }^{5}$, \\ Johnny R J Fontaine ${ }^{6}$, \\ Charles Harb ${ }^{7}$, Jan Cieciuch ${ }^{8}$, \\ Mustapha Achoui ${ }^{9}$, \\ Ma Socorro D Mendoza ${ }^{10}$, \\ Arif Hassan ${ }^{11}$, \\ Donna Achmadi ${ }^{1,12}$, \\ Andrew A Mogaji ${ }^{13^{\prime}}$ and \\ Amina Abubakar ${ }^{14}$
}

\footnotetext{
${ }^{1}$ School of Psychology, Victoria University of Wellington, Kelburn Parade,

PO Box 600, Wellington 6012, New Zealand;

${ }^{2}$ Salgado de Oliveira University, Rio de Janeiro, Brazil; ${ }^{3}$ International Management \& Innovation Department, School of Business, Middlesex University, London, UK; ${ }^{4}$ Department of Business Administration, College of Business

Administration, Winona State University, Winona, USA; ${ }^{5}$ Department of Psychology, National Chung Cheng University, Chiayi, Taiwan, ROC;

${ }^{6}$ Department of Personnel Management, Work and Organizational Psychology, Ghent University, Ghent, Belgium; ${ }^{7}$ Department of Psychology, American University of Beirut, Beirut, Lebanon; ${ }^{8}$ University Research Priority Program Social Networks, University of Zurich, Zurich, Switzerland; ${ }^{9}$ Arab Open University, Kuwait, Al-Ardia Aradia, Kuwait; ${ }^{10}$ UBHC, Rutgers University, Union, NJ, USA; ${ }^{11}$ International Islamic University Malaysia, Kuala Lumpur, Malaysia;

${ }^{12}$ Canterbury District Health Board, Hillmorton
}

Online publication date: 17 October 2018
Hospital, Christchurch, New Zealand; ${ }^{13}$ Department of Psychology, Benue State University, Makurdi, Nigeria; ${ }^{14}$ Department of Psychology and Public Health, Pwani University, Kilifi, Kenya

Correspondence:

R Fischer, School of Psychology, Victoria University of Wellington, Kelburn Parade, PO Box 600, Wellington 6012, New Zealand.

Tel: +64 4463 5373;

Fax: +64 4463 5420;

e-mail: Ronald.fischer@vuw.ac.nz

Journal of International Business Studies (2019) 50, I35-136.

https://doi.org/|0.1057/s4|267-018-0174-4

The online version of this article is available Open Access

CORRECTION TO: JOURNAL OF INTERNATIONAL BUSINESS STUDIES (2017).
https://doi.org/10.1057/s41267-017-0132-6

The article Does organizational formalization facilitate voice and helping organizational citizenship behaviors? It depends on (national) uncertainty norms, written by Ronald Fischer, Maria Cristina Ferreira, Nathalie Van Meurs, Kubilay Gok, Ding-Yu Jiang, Johnny R J Fontaine, Charles Harb, Jan Cieciuch, Mustapha Achoui, Ma Socorro D Mendoza, Arif Hassan, Donna Achmadi, Andrew A Mogaji and Amina Abubakar, was originally published electronically on the publisher's internet portal (currently SpringerLink) on 21 December 2017 without open access.

With the author(s)' decision to opt for Open Choice the copyright of the article changed on June 2018 to (c) The Author(s) and the article is forthwith distributed under the terms of the Creative Commons Attribution 4.0 International License (http://creativecommons.org/licenses/by/4.0/), which permits use, duplication, adaptation, distribution and reproduction in any medium or format, as long as you give appropriate credit to the 
original author(s) and the source, provide a link to the Creative Commons license and indicate if changes were made.
Open Access This article is distributed under the terms of the Creative Commons Attribution 4.0 International License (http:// creativecommons.org/licenses/by/4.0/), which permits unrestricted use, distribution, and reproduction in any medium, provided you give appropriate credit to the original author(s) and the source, provide a link to the Creative Commons license, and indicate if changes were made. 